\title{
An Introduction to Forensic Geosciences and Its Potential for Iran
}

\author{
S.A. Mazhari \\ Department of Geology, Payame Noor University (PNU), Sabzevar, Iran \\ Tel: 9857-1264-4012Ｅ-mail: s_mazhari@pnu.ac.ir
}

\begin{abstract}
Forensic geoscience (geoforensics) is the application of earth sciences to receive reality. There is not enough knowledge about geoforensics in Iran, and so, in this paper the best applications are reviewed. Forensic geoscience can be divided to four major groups: pedology, mineralogy and petrology; geophysics; natural geography and geoscience; remote sensing, location data and Geographic information System (GIS). Forensic geosciences have many applications in both of civil and criminological investigations in many private- and governmental organization of Iran such as police, military services, Justice, Environmental organizations, Petroleum Ministry, Energy Ministry, etc. The best approach to establish and develop geoforensics in Iranian society is to create graduate forensic geoscience disciplines by cooperation of different specialist from various sciences.
\end{abstract}

Keywords: Forensic geoscience, Geophysics, Remote sensing, Geomorphology, Mineralogy, Iran

\section{Introduction}

Forensics has been defined as the application of scientific principles and methods usable in the court (e.g. Saferstein, 2002). Thus, forensics collects evidence to solve security and criminal problems. Forensics uses all sciences (medicine, chemistry, physics, biology ...) to get reliable scientific evidence. Therefore, it has many sub-disciplines. According to above definition, there is close relations between law and forensics so that forensic sub-disciplines have been described by legal prefix in literatures. The best known phrase for Iranians is legal medicine which has the same meaning to forensic medicine. However, the use of 'legal' emphasizes on only one aspect of forensic applications, i.e. credible evidence for the court. Today, forensics includes all scientific efforts to discover truths in all aspects not only for court scenes.

Forensic geoscience (Geoforensics) is one of the most important sub-disciplines of forensics. Forensic geoscience utilizes geological principles and methods to find reality. Attention to the forensic geoscience have been growing during recent years in order that related published articles increased enormously by 2000 (Ruffell and McKinley, 2005). There are more than 200 courses on forensic sciences include substantial geoscience elements (Chamakura, 2001).

Although, the main application of forensic geoscience is preparing of reliable evidence to present in a court, but as discussed before, forensic geoscience is composed of whole domain of fact detection and can be used in military and security organs, information services, NGOs, and even industrial and research centers.

Due to geoforensics key role in forensic activities, it is necessary to explain its important for Iranian specialists. The lack of public knowledge about forensic geoscience in Iran led to unawareness of many people, even forensic scientists, about its importance. For these reasons, in this article an introduction to forensic geosciences is addressed with emphasis on the applications in Iranian society. The first section gives a brief history of the development of geoforensics. Then, major sub-disciplines have been explained regarding to Iran requirements; and finally, the best approaches for development of forensic geology in Iran have been suggested.

\section{Forensic geoscience history}

Old documents show primary rules of forensic geology had been used in China and India before 1800s (Ruffell and McKinley, 2005). The first application of forensic geoscience ascribed to fable detective, Sherlock Holmes, created by Arthur Canon Doyle (1859-1930). Canon Doyle was graduated in natural science from Cambridge and had enough geological knowledge. He used rocks and bridges evidence in his stories. In one story, titled as Scarlet, Holmes had high capability to distinguish different soil types and guessed the location of people by shoes and clothes mud (Muarry and Tedrow, 1992).

During the late 1800 s to middle 1900 s, forensic geoscience was used by scientists with individual theories and methods such as Edmond Locard and Georg Pop. The first Forensic Science and Criminology School was 
established by Rodolphe Reiss in Lusan University in 1909 (http://www?unil.ch/ips/naval.html) and private Locard Pollice Laboratory begun working in 1910. Forensic geoscience techniques were one of the most practical methods for them. During 1930s-1970s, geoforensics and related fields (soil sciences, botanology, etc.) managed by governmental organizations such as FBI in USA and Aldermaston in UK (Ruffell and McKinley, 2008).

In 1975, Muarry and Tedrow wrote a text book about forensic geology and resulted in basic evolution in geoforensics. By re-writing of this book in 1992, widespread range of geoscience applications appeared. Then, interest to forensic geoscience increased and cooperation between geologist and other forensic scientists led to formation of new classes of geoforensics. In recent years and by using of new analytical techniques, forensic geoscience data have more reliability, so that they are more interesting. Comprehensive review of these activities and complete list of famous forensic geologists has been reported by Ruffell and McKinely $(2005 ; 2008)$ and Pye (2007).

\section{Sub-disciplines of forensic geosciences}

As discussed above, geoforensics cover widespread range of information and has close relations to other basic sciences. So, it is possible to divide forensic geoscience to abundant sub-disciplines, although, they may overlap in many cases. Some classifications have been suggested; for example Ruffell and McKinley (2005) divided forensic geology to two orders: large scales and small scales. Although, the boundary between large and small scales is arbitrarily in many positions, they believed that forensic geophysics, geomorphology and remote sensing are large scale, whereas, forensic mineralogy and geochemistry are small scale. However, in a common forensic research, we have to use different methods contemporaneously regarding to time, technical and financial limitations. In this paper, the most useful applications of forensic geosciences in addition to their properties are presented for Iran. In this regard, forensic geoscience is grouped to four categories: 1- forensic pedology, mineralogy and petrology; 2- forensic geophysics; 3 - forensic natural geography and geomorphology; 4- forensic remote sensing, location data and Geographic Information System (GIS). A concise description of each category will be explained and the capability of geoforensics in Iran will be discussed; and finally, suitable suggestions for establishment and development if forensic geoscience in executive, justice and research organizations will be presented.

\subsection{Forensic application of soil, mineralogy and petrology}

The importance of soil, rocks, minerals and sediment studies in criminal investigations has been established since100 years ago, although, the first users were not geologist (Murray and Tedrow, 1975; 1992). Professor Hans Gross (1847- 1915), an Austrian criminologist, wrote his classic book titled as Hanbuch fur Untersuchungsrichter (Handbook for Examining Magistrates) and showed the worth of microscopic study of minerals in dust samples and soil of shoes [Pye, 2007]. Two of his advocators, i.e. Georg Popp and Edmond Locard, followed his suggestions and used them in real cases. They studied the composition of dirt on clothing, footwear, and in fingernail scrapings and applied the information in a number of murder investigations (Muarry, 2004). The application of geological evidence in forensic studies got more attention after 1975 when Muarry and Tedrow published a first text book in this issue, but there is only limited dedicated literature in this field and there is widespread ignorance among forensic scientist about its potential (e.g. Townley \& Ede, 2004).

Really, earth surface materials have enormous diversity and by means of modern techniques, it is possible to make very detailed properties and discriminate materials which are potentially highly useful in forensic researches. Forensic geoscience techniques and information are practical in a wide range of civil and criminal and even military issues such as environmental accidents, natural hazards, constructional failures, pollution and of coarse, serious crimes like murder, terrorism, nuclear weapons, genocide, arson, drug smuggling and rape.

Forensic studies of soils, minerals and rocks depend on different conditions which the most issues are: the experience of researcher, equipments, time and financial limitations. In this regard, studies can be restricted to the use of hand samples, binocular and polarizing microscope, or would be progressed by modern techniques such as XRF, XRD, QXRD, LA-ICP, ... . Houck (2003) and Junger (1996) give overviews of forensic applications of soils and minerals. These authors follow Palenik's procedure in terms of sequence of soil analysis, from analysis of colour, organic content, coarse and fine fraction microscopy, heavy and light mineral identification and then specialist studies (Ruffell and McKinley, 2005). The section of specialist studies is the most controversial part of forensic soil, mineral and sediment researches. There are debates about which methods are better, for example density column becoming popular, then falling from favour and recently resurfacing as a possibly viable method (Petraco and Kubic, 2000). X-ray diffraction (XRF) have been remained a trustworthy method to compare rock, sediment and soil in forensic investigations (Muarry, 2004). Likewise, X-ray powder 
diffraction (XRD) remains the best available technique to identify minerals in fine-grain materials such as soils, rock dust, building debris or rocks and artificial materials (Srodon et al., 2001; Pye, 2007).

ICP analysis of rock, sediment, and soil materials is normally undertaken after dissolution of the powdered material using acids or alkalis; in some preparation procedures, a lithium metaborate fusion stage may also be employed (Jarvis et al., 2003; Thompson and Walsh, 2003). Analysis is performed either by ICP-AES and ICP-MS separately, or in combination. However, it is also possible to analyze rocks, mineral grains, and fossils without crushing and dissolution, using laser ablation ICP-MS (Sylvester, 2001).

\subsection{Forensic application of geophysics}

Forensic geophysics is not formally defined or listed in the encyclopedic dictionary of exploration geophysics (Sherriff, 1994), but is could be defined as 'the application of geophysical methods related to discern reality' (modified from Fenning and Donnelly, 2004) or using of geophysical approaches to get forensic evidence'. These methods could equally apply to both criminal and civil investigations, to which might help in military operations, for example during Word War I, the location of enemy artillery guns was detected by seismic techniques (Fennning and Donnelly, 2004). In the last 30 years, forensic geophysics could conduct highresolution surveys of the top 1-2 m below ground surface by means of geophysical methods in archaeological surveying and advances in geophysical instruments and computing technology. Some of these methods are given in Watters and Hunter (2004).

Reynolds (1997) classified geophysical applications in forensics to environmental geology, engineering, exploration (mining, hydrocarbons), hydrogeology (and glaciology) and archaeology. Geophysical methods can be divided to active methods and passive methods. In active methods artificial methods are produced and their increase/decrease will be measured; and in passive methods, special instruments measure natural properties of the ground (Ruffell and McKinley, 2008). In forensic studies both methods are used. One of the most known forensic applications of geophysics methods is searching for buried materials (e.g. Watters and Hunter, 2004; Ruffell and McKinley, 2008). Discovering of buried materials has important value in different forensic studies such as environmental problems, illegal digging, hidden weapons or hidden smuggled goods, etc. The principles which apply in forensic geophysics are similar to other geophysical researches but the goals may be different. The applicability of geophysical methods in forensic surveys can be summarized as seismic methods, magnetic methods, resistivity method, Induced polarization method, self- potential method, electromagnetic method, metal detector method and gravity method (Fennning and Donnelly, 2004; Ruffell and McKinley, 2008). These methods have individual characteristics which are suitable for different case studies. Furthermore, the sensibility and reliability of resulted data differ in various situation and assorted materials and geophysicist experience may affect on the interpretation of these data.

\subsection{Forensic application of natural geography and geomorphology}

Possibly the most fundamental and straightforward application of natural geography and geomorphology in forensics relates to criminal aspects. Geomorphology (the science of study of surface phenomena and landforms) has a key role in criminal investigations and natural or accidental disasters, especially in non-urban environments (Ruffell and McKinley, 2008). Geomorphologist acts as a landscape detective and gets reply to the questions such as: what happens here? When does it happen? why does it happen? and .... These information will produce valuable forensic results. The best forensic application of geomorphology is landscape interpretation which needs to confidence and experience of forensic scientist such as Douglas Owsley (Owsley, 1995). Owsley showed that how simply measured dips, hummocks, vegetation and drainage change in an area, followed by simple physical probing in a forensic investigation can prevent expensive, destructive and time- consuming excavation (Ruffell and McKinley, 2005). This method was followed by Imaizumi (1974) and was justified by Elwood et al. (1994). They combined study of vegetation, geomorphology, photographs and geophysics to reach a highly striking research (Ruffell and McKinley, 2005).

\subsection{Forensic application of remote sensing, location data and Geographic Information System (GIS)}

In remote sensing methods, data are obtained by indirect sampling from surface and under-surface of the ground. Some of geophysical methods are very far remote sensing so that the boundary between them will be arbitrary. Remote sensing methods have noticeable function in forensic studies. A comprehensive overview of aerial photography, satellite imagery and global positioning systems applications to forensic investigations is given by Brilis et al. (2000a,b) and Grip et al. (2000). These applications contain environmental forensic investigations such as mapping of hidden industrial waste and the non- intrusive examination of crime scenes (Ruffell and McKinley, 2005). The emission of gases into the atmosphere could be discerned by remote sensing methods (Ruffell, 2002). A standard first approach in many forensic studies is infrared and ultra-violet photography of 
scene in order to detect ground distraction and tyre movement positioning (Ruffell and McKinley, 2005). Other common application of remote sensing methods comprised of the monitoring of water currents to predict where bodies, toxic waste or munitions may be washed ashore (Hardisrty, 2003).

Geographical information has close relations to regional map. Due to advancing in computer technology plotting, saving, comparing, processing and data analyses are performed in a rapid and high quality form by means of Geographic Information System (GIS). Today, GIS is used in all sections and activities such as statistics, mapping, source and waste management, urban planning and etc. GIS have found most use in criminology in the prediction of crime and thus the targeting of police resources to certain geographic areas (Hirschfield and Bowers, 2001). GIS has been justified in court many times, for example Brodsky (2002) showed how a dishonest claim for income loss from retail stores could be inspected by geographically spread income over a wide range using GIS. A GIS mapping for forensic investigations is now ordinary (Ruffell and McKinley, 2008).

\section{Discussion}

Regarding what is discussed in previous sections, different branches of geosciences have important role in the discovering of real facts in forensic investigations. Forensic geoscience presents valuable approaches for many mankind activities, and its applications aren't limited to security and military organizations. All institutions and organizations (governmental or private) need to access actual facts of major factors controlling the accidents formation. It helps them to do better programming and increase executive quality. Therefore, forensic geoscience can be used in widespread scales and facets. Moreover, it has strong scientific potential and extensive relations to other sciences, so that it could connect different branches and help to develop science borders. It would be managed to use this dynamic science and improve scientific researches in Iran, too. Furthermore, we can take its advantage to solve many forensic problems. The most popular application of forensic geology relates to legal investigations which can be very applicable for Iran. In addition to normal application of forensic geology in common criminology, it has high capacity to relieve some terrible destructive actions such as terrorism which is serious problem in our neighborhoods. Different forensic geoscience methods (e.g. mineralogy, geophysics, soil sampling, remote sensing, geomorphology and GIS) have key role in real forensic investigations against terrorism (see related examples in Ruffell and Mckinley, 2008). In addition to criminological and military application of forensic geoscience, it has much capability in civil problems which are concerned with a lot of Iranian organizations such as environmental organization, Justice Formations, municipalities and related organs, Petroleum Ministry, Energy Ministry, Agriculture Ministry and etc. Therefore, there is high capacity for using of forensic geology in Iran, but unfortunately, the public awareness, even between Iranian specialists, is low and firstly, it is necessary to base the importance of forensic geology between forensic scientist and forensic workers (i.e. officers in related organizations). Fortunately, there are pleasant potential in Iran to develop forensic geology: there are many graduated geologist in different branches of earth science who could be learned by suitable courses; and use them in different investigations. However, to design a fundamental approach for implement of forensic geology (both practical and theoretical) in Iran, it is necessary to prepare required specialist by academic manner. In this regard two different approaches can be suggested:

1- To plan and manage suitable courses related to forensic geology in military universities. In these courses formal police officer would be trained to know the importance of forensic geology, correct sampling and safekeeping of samples, primary stages of data gathering and etc.

2- To create new branches related to forensic geology in Iranian universities. This could be done on undergraduate and/or graduate levels; but regarding to Iranian conditions and available specialist, it is better to begin by graduate studies. During graduated researches, it is possible to use of different specialist of all scientific groups. If do this, in mean-time, we have enough specialists to design undergraduate sub-disciplines in various forensic geoscience branches.

\section{Conclusion}

Forensic geosciences can be defined as a sub-discipline of geoscience that is concerned with the application of geological and wider environmental science information and methods to detect true evidence. Forensic geoscience can be useful for both of civil and criminal investigations. There are suitable field for developing forensic geoscience in Iran. Different governmental and private Iranian institutions and organization can utilize geoscience principles in forensic investigations. Since there is not public acknowledgment, and due to the lack of forensic geologist in Iran, it is essential to create new branches in Iranian universities. With regards to Iranian condition, it is suggested to design related graduated forensic geoscience sub-discipline in the first step. 


\section{References}

Brilis, G.M., Gerlach, C.L., van Waasbergen, R.J. (2000a). Remote sensing tools assist in environmental forensics: Part I. Digital tools - traditional methods. Environmental Forensics, 1, 63- 67.

Brilis, G.M., van Waasbergen, R.J., Stokely, P.M., Gerlach, C.L. (2000b). Remote sensing tools assist in environmental forensics: Part II. Digital tools. Environmental Forensics, 1, 1- 7.

Brodsky, H. (2002). GIS goes to court making a case for forensic mapping. Geo Info Systems, 12 (3), 48.

Chamakura, R.P. (2001). [Online] Available: http://www.forensicpage.com/new05.htm (accessed 30/6/2004).

Ellwood, B.B., Owsley, D.W., Ellwood, S.H., Mercado-Allinger, P.A. (1994). Search for the grave of the hanged Texas gunfighter, William Preston Longley. Historical Archaeology, 28, 94- 112.

Fenning, P.J., Donnelly, L, J. (2004). Geophysical techniques for forensic investigation. In: Pye, K., Croft, D.J. (eds) Forensic Geoscience: principles, techniques and applications. Special Publications of the Geological Society of London, 232, 11-20.

Grip, W.M., Grip, R.W., Morrison, R. (2000). Application of aerial photography in environmental forensic investigations. Environmental Forensics, 1, 121- 129.

Hardisty, J. (2003). Hydrodynamic modelling as investigative and evidential tools in murder enquiries: examples from the humber and thames. In: Pye, K., Croft, D. (Eds.), Forensic Geoscience: Principles, Techniques and Applications. Conference Abstracts, Geological Society of London, 3-4 March 2003, p. 29.

Hirschfield, A., Bowers, K. (Eds.). (2001). Mapping and Analysing Crime Data: Lessons from Research and Practice. Taylor and Francis, London. 312 pp.

Houck, M.M. (Ed.). (2003). Mute Witnesses. Academic Press, London. 188 pp.

Imaizumi, M. (1974). Locating buried bodies. FBI Law Enforcement Bulletin, 43, 2 -5.

Jarvis, K.E., Gray, A.L., and Houk, R.S. (2003). Inductively Coupled Plasma Spectrometry. Viridian Publishing, Surrey, 380pp.

Junger, E.P. (1996). Assessing the unique characteristics of closeproximity soil samples: just how useful is soil evidence? Journal of Forensic Sciences, 41, 27- 34.

Murray, R.C. and Tedrow, J.C.F. (1975). Forensic Geology. Rutgers University Press, New Brunswick, New Jersey, 217pp.

Murray, R.C. and Tedrow, J.C.F. (1992). Forensic Geology, 2nd ed. Prentice Hall Inc., Englewood Cliffs, New Jersey, 203pp.

Murray, R.C. (2004). Evidence from the Earth: Forensic Geology and Criminal Investigation. Mountain Press Publishing Company, Missoula, Montana, 226pp.

Petraco, N., Kubic, T. (2000). A density gradient technique for use in forensic soil analysis. Forensic Science International, 4, 872-873.

Reynolds, J.M. (1997). An introduction to applied and environmental geophysics. John Wiley \& Sons, Ltd, Chichester.

Owsley, D.W. (1995). Techniques for locating burials, with emphasis on the probe. Journal of Forensic Science, 40 (5), 735-740.

Pye, K. (2007). Geological and soil evidence forensic applications, CRC Press, Taylor \& Francis group, 340 pp.

Ruffell, A. (2002). Remote detection and identification of organic remains: an assessment of archeological potential. Archaeological Prospection, 9, 115-122.

Ruffell, A., McKinely, J. (2005). Forensic geoscience: applications of geology, geomorphology and geophysics to criminal investigations. Earth-Science Review, 69, 235-247.

Ruffell, A., McKinely, J. (2008). Geoforensics. John Wiley \& Sons, Ltd.

Saferstein, R.E. (2002). Forensic Science Handbook. Prentice Hall, New Jersey, 784 pp.

Sheriff, R.E. (1994). Encyclopedic dictionary of exploration geophysics. Society of Exploration Geophysics, Tulsa.

Srodon, J., Drits, V.A., McCarty, D.K., Hsieh, J.C.C., Eberl, D.D. (2001). Quantitative X-ray diffraction analysis of clay-bearing rocks from random preparations. Clays and Clay Minerals, 49, 514- 528. 
Sylvester, P. (ed.). (2001). Laser-Ablation-ICPMS in the Earth Sciences: Principles and Applications. Mineralogical Association of Canada Short Course Series Volume 29, Mineralogical Association of Canada, Ottawa, 243pp.

Thompson, M. and Walsh, J.N. (2003). Inductively Coupled Plasma Atomic Emission Spectrometry. Viridian Publishing, Woking, Surrey. 316pp.

Townley, L., Ede, R. (2004). Forensic Practice in criminal cases. The Law Society, London.

Watters, M., Hunter, J.R. (2004). Gephysics and burial: field experience and software development. In: Pye, K., Croft, D.J. (eds) Forensic Geoscience: principles, techniques and applications. Special Publications of the Geological Society of London, 232, 21-33. 